OPEN ACCESS

Authors' contribution:

A) conception and design of the study

B) acquisition of data

C) analysis and interpretation of data

D) manuscript preparation

E) obtaining funding

\section{Structure of Achievement Motivation Dispositions in Elite and Non-Elite Track and Field Athletes}

\author{
Anna Pietrzak ${ }^{\mathrm{A}-\mathrm{D}}$, Aleksandra Tokarz ${ }^{\mathrm{A}-\mathrm{D}}$ \\ Jagiellonian University, Kraków, Poland
}

ABSTRACT

Achievement motivation is a distinguishing disposition in elite and non-elite athletes. Implicit theories and competence perception influence the types of achievement goals and constitute separate achievement motivation dispositions. The context of sport promotes various achievement goals and implicit theories about athletic competence. For this reason, scientific research should focus on the intrapersonal profiles of achievement motivation dispositions (achievement goals, implicit theories, and competence perception) instead of specifying only one of them. This study explores differences between elite and non-elite athletes in terms of intrapersonal profiles of achievement motivation dispositions. 54 elite and 50 non-elite track and field athletes took part in the study. The results suggest that athletes tend to perceive their competence accurately. Cluster analysis of the studied dispositions was conducted. The clusters present sets of achievement dispositions that vary in intensity. Moreover, the results present trends of the differences between elite and non-elite athletes in two of the three clusters obtained in the study.

KEYWORDS Achievement motivation, achievement goals, implicit theories, athletic competence, track and field athletes

\title{
Introduction
}

McClelland $(1955,1986)$ defined achievement motivation as the need for competition with standards of individual excellence. The need for competition can be understood as striving to improve or maintain one's abilities in significant areas, in which personal standards or patterns of excellence apply to. Adopting standards translates into understanding one's performance as success or failure. The main assumption in this conceptualisation is that motives are dispositions to recognize standards and requirements in real life events and situations (Dąbrowska, 1991). Another broad achievement motivation framework (Tokarz \& Kaleńska- Rodzaj, 2011) focuses on the competence and is represented by the constructivist concepts of Nicholls (1984) and Dweck (Dweck \& Leggett, 1988). The common core of the concepts is the link between beliefs about the nature of traits (abilities), referred to as implicit theories, and behavioural patterns that are salient in the context of achievement (Moller \& Elliot, 2006). Implicit theories direct individuals toward different concepts of success. Individuals who perceive their ability as a fixed entity (Dweck \& Leggett, 1988) believe they have succeeded in a task if they managed to complete it without effort, or if others (a normative group) had to put more effort into the task to gain the same result. In essence, these individuals seek performance. Conversely, those convinced about the malleable quality (Dweck \& Leggett, 1988) of the trait identify success with effort and 
competence gain (Jagaciński \& Strickland, 2000) and seek mastery in a task. This distinction, which represents the bifactor model of achievement motivation, has been broadly discussed and explored in various studies (see: Dweck \& Leggett, 1988; Elliot \& Dweck, 1988; White \& Duda, 1993).

However, Elliot and Harackiewicz (1996) argue that the bifactor model of achievement motivation does not go beyond description of appetitive forms of behaviour. Despite antithetical incentives, both learning and performance goals are associated with approaching, not avoiding, challenge. Elliot and Harackiewicz (1996) noticed a relationship between belief about the level of competence in a task and the execution of the task by individuals who adapt performance goals. This link is a consequence of the core beliefs that are characteristic of individuals who pursue performance goals; namely, that important traits such as intelligence in an educational context (Elliot \& Dweck, 1988) or athletic skill in a sport context (Duda \& Nicholls, 1992) are inborn and intractable to changes. If a skill is not susceptible to change, then its current level conditions general selfevaluation regarding the skill. With high entity belief, self-evaluation is advantageous for individuals who perceive their current competence as high and is disadvantageous for those who perceive their current competence as low. The former disposition leads to engaging in an activity with anticipation of a rewarding outcome, whereas the latter leads to avoiding the activity or engaging in it with the purpose of not showing incompetence (Church \& Elliot, 1997; Moller \& Elliot, 2007).

The aforementioned findings led researchers to distinguish three forms of achievement motivation: mastery orientation, performance-approach orientation, and performance-avoidance orientation. In a further development of achievement goals theory, Elliot and McGregor (2001) analysed the definition and value dimensions of competence. When defining competence, one can refer to the absolute standard that is based on task characteristics, the intrapersonal standard that is based on its current individual level, or the interpersonal standard that is dependent on the level of the normative group (McClellenad, 1986; McClelland et al., 1995, in: Negru, 2009). The absolute and intrapersonal standards, which are empirically and conceptually indistinguishable, comprise the mastery goal, whereas the interpersonal standard translates into a performance goal in achievement motivation. The aforementioned approach and avoidance behaviour tendencies constitute a value dimension of competence. The four achievement goals (Elliot \& McGregor, 2001) include

1) mastery-approach goal,

2) mastery-avoidance goal,

3) performance-approach goal and

4) performance-avoidance goal.

Recognition of these four achievement motivation goals gave rise to further questions regarding their links with antecedent characteristics, namely implicit theories (Van-Ypeen \& Duda, 1999) and the perception of current competence (Elliot \& Church, 1997; Nien \& Duda, 2008). In the context of sport, implicit theories take the form of beliefs about the causes of success - assumptions of what is necessary to achieve desirable effects such as results, rewards, and position (Van-Yperen \& Duda, 1999). In the beliefs of athletes, success may be determined by their effort, their ability (understood as inborn talent), illegal advantages, or by other external factors that they cannot influence (Duda \& Nicholls, 1992; White \& Duda, 1993). As indicated previously, the perception of competence plays a significant role in shaping the valence (approach-avoid) of achievement motivation.

Conroy and colleagues (Conroy, Elliot \& Hofer, 2003) were the first to test the four-factor model in the context of sport. Confirmatory analysis supported the validity of the model among recreational athletes. With the exception of the mastery-approach orientation, all orientations were positively correlated with fear of failure. The implicit assumption of this study was the mutually exclusive nature of the achievement goals. This approach was questioned in studies on the motivational and emotional consequences of pursuing multiple achievement goals (Barron \& Harackiewicz, 2001; Harackiewicz, Barron \& et al., 2002; Jang \& Liu, 2012). Wang and colleagues (Wang, Biddle \& Elliot, 2007) extended this framework in the context of physical activity in their study of teenagers from Singapore (2007). They analysed intrapersonal profiles comprising different levels of 
achievement goals for groups of teenagers. Students scored either low, moderate, or high in each of the four goals, which translated into three clusters. The fourth cluster comprised students who scored high in mastery goals and medium in performance goals. However, it was the third cluster (high results in all of the achievement goals) that was associated with most adaptive characteristics and outcomes; namely, the highest perceived competence, the lowest amotivation, the most engagement in physical activity and the most enjoyment of it (Wang, Biddle \& Elliot, 2007). These results are in line with earlier findings about the motivational benefits of pursuing both task and ego goals, also defined as mastery and performance goals, the combination of which facilitates engagement in competitive sport (Biddle \& Wang, 2001).

The mutual independence of achievement goals is especially legitimate in the context of sport (Sarrazin, Biddle, Famose, Cury, Fox \& Durand, 1996, in: Biddle, Wang, Chatzisarantis \& Spray, 2003) because task and ego involvement do not exclude each other in the structure of athletes' goals. The concept of ability, understood as a talent, refers to congenital human attributes which can only be slightly affected by an athlete. On the other hand, athletic skills like strength, endurance or technical proficiency can be developed in regular training. Sarrazin et al (1966, in: Biddle et al., 2003) claim that belief in the fixed nature of sporting abilities does not preclude the belief that effort can bring the desired results. The leading issue for professionals involved in physical activity on a competitive level is what differentiates successful individuals from those who underachieve. The focus of this research was to explore the correspondence between the level of the athletes' sporting achievements and trends in intrapersonal achievement dispositions.

Alluding to the concepts of Dweck (1986) and Nicholls (1984) regarding the links between implicit theories, perceived competence and achievement goals, our aim was to explore the link between the level of the athletes' sporting achievements and motivational dispositions. We followed Wang and colleagues' (Wang, Biddle \& Elliot, 2007) postulate about the independence of the four achievement motivation goals and developed it by exploring motivational profiles of elite and non-elite athletes. The objective of this study was to explore the motivational profiles of elite and non-elite athletes. We hypothesized that the two groups' profiles would differ in that higher-class athletes show stronger propensity for adaptive dispositions: mastery and approach goals, the belief that effort is the cause of success, and the perception of high competence. It was expected that lowerclass athletes would show a tendency to score higher in less adaptive dispositions: performance and avoidance goals, the belief that ability and external factors are the causes of success, and the perception of low competence.

\section{Methods}

116 track and field athletes (51.8\% male) who were members of Academic Sport Associations from various Polish cities ${ }^{1}$ participated in the study. Due to incomplete responses in 4 sets of questionnaires, 112 data sets were analysed further. Athletes were 19-28 years old with a mean age of 21.5 ( $\mathrm{SD}=1.9$ ). The sporting level of the participants varied: $1.8 \%$ were international master athletes, $9.8 \%$ master athletes, $36.6 \%$ first-class athletes, $23.2 \%$ second-class athletes, $20.5 \%$ third-class, $0.9 \%$ lower-class athletes. $7.1 \%$ of the athletes did not define their sporting level. The first three groups (MM, M, first-class) were categorized as elite athletes (48.2\%); the three latter groups were categorized as non-elite athletes (compare: Gierczuk et al., 2012). This classification was applied in pursuit of accordance with the definition of an elite athlete introduced by Swann, Moran, and Piggott (2015). Most of the sample categorized here as higher-class athletes fit the description of Successfulelite or at least Competitive-elite (see: Swann, Moran \& Piggott, 2015). Athletes represented various athletic disciplines: sprinting (17.9\%), hurdling (16.1\%), middle distance running $(19.8 \%-400 \mathrm{~m}, 800 \mathrm{~m}, 1500 \mathrm{~m})$, long distance running (13.5\%), jumping (18.9\% - high, long, an triple jumping, there were no pole vault

\footnotetext{
${ }^{1}$ Academic Sport Association is a Polish student sport organization. ASA associates athletes from various disciplines, including track and field. Many ASA members belong to Polish national teams and represent Poland in international sport events, including the Olympics. ASA official site: http://www.azs.pl/
} 
representatives), race walking (1.8\%), athletic throwing (6.3\% - discus, javelin, shotput, hammer), steeplechase $(1.8 \%)$.

Questionnaires were distributed to athletes indirectly through track and field coaches as well as by 'snowball sampling' and directly during the Polish Academic Athletic Championships. Every participant was asked to complete three questionnaires: the Achievement Goals Questionnaire ${ }^{2}$ (1), the Sport Belief Questionnaire (2) and the Perceived Sport Competence Questionnaire (3). The Polish adaptation (Wojdyło \& Retkowski, 2012) of Elliot and McGregor's (2001) Achievement Goals Questionnaire (1) was applied to examine achievement goals in the study sample. The original version of the questionnaire was designed for employees but for the purposes of the study it was precluded by a request to take it from the perspective of an athlete. Like the original (Elliot \& McGregor, 2001) instrument, the questionnaire measures four kinds o achievement goals: masteryapproach, mastery-avoid, performance-approach and performance-avoid. Research conducted on 387 participants supports the satisfactory reliability of the Polish adaptation and the good fit of the four-factor model (Wojdyło \& Retowski, 2012). In the current research we added two questions after the questionnaire to determine whether participants had given answers from the perspective of athletes.

The Sport Belief Questionnaire (2) was adapted (Duda \& Nicholls, 1992) to measure implicit theories about the causes of success. The original instrument consists of 18 items that make up four subscales: Effort, Deception, Ability, and External Factors. Each subscale refers to different beliefs about the causes of success in sport. The Effort subscale relates to beliefs that hard work, training, and passion lead to success. The Deception subscale concerns illegal advantages such as cheating. The Ability subscale refers to an inborn talent as the primary cause of success, and the External Factors subscale deals with uncontrollable variables like luck or equipment. Back translation (from English to Polish and backwards) was implemented in the process of adaptation. The internal reliability of the model fit for the adaptation was conducted using SPSS 22. Principal axis factoring alongside theoretical background reflections resulted in a four-factor model which explained $46.8 \%$ of variance. Kaiser oblique rotation resulted in a solution with 14 items. The reliability of the scale was close to the recommended level as Cronbach's $\alpha$ was 0.66 (Bedyńska \& Cypryańska, 2013).

Athletes' subjective estimation of their present competence in sport activity was measured by the short Perceived Sport Competence (3) scale that was designed in Polish for the purpose of the study. The participants responded to 5 statements on a 5-point Likert-type scale. The reliability (Cronbach's $\alpha$ ) of the scale was 0.81 . The scale was specifically developed for the context of competitive sport and focused on competence in this field instead of general self-efficacy, as was employed in the Polish studies by Juczyński (2000).

\section{Results}

The role of sporting level (elite/non-elite) in the variability of motivational dispositions is presented in Table 1. Links between sporting level and all the motivational dispositions (beliefs about the cause of success, perceived competence, and achievement goals) were tested using a MANOVA test in SPSS 24 software. Levene's test for homogeneity of variance shows that all the dependent variables met its assumption. However, according to the Shapiro-Wilk test, only perceived competence and the mastery-avoid orientation goal met the assumption of normal distribution. There was a statistically significant difference in motivational dispositions based on the athletes' sporting level, $\mathrm{F}(8,102)=2.08, \mathrm{p}<.05$; Wilk's $\lambda=.858$; partial $\mathrm{n}^{2}=.142$. However, a follow up ANOVA showed that the only significant effect on the perceived competence in sport was that of sporting level (elite vs. non-elite); $\mathrm{F}(1,110)=11.96 ; \mathrm{P}=.001$. Elite athletes tended to perceive their current sporting competence as higher $(\mathrm{x}=3.47, \mathrm{sd}=.72)$ than non-elite athletes $(\mathrm{x}=2.99, \mathrm{sd}=.74)$.

\footnotetext{
${ }^{2}$ The Achievement Goals Questionnaire registers responses on 7-point, Likert-type scale; the Sport Belief Questionnaire and Perceived Competence both register responses on 5-point, Likert-type scale. The athletes' results in the three scales were standardized in further statistical analysis.
} 
Table 1. Effects of sporting level on motivational dispositions

\begin{tabular}{lcccc}
\hline \multirow{2}{*}{ Dispositions } & \multicolumn{2}{c}{ Sporting level } & & \\
& Elite & Non-elite & F & p \\
\hline master_approach & 5.86 & 5.63 & 1.37 & .24 \\
master_avoid & 4.42 & 4.37 & .04 & .83 \\
perform_approach & 4.98 & 4.65 & 2.06 & .16 \\
perform_avoid & 4.98 & 4.65 & 2.06 & .16 \\
comp_sport & 3.47 & 2.99 & 11.96 & $.00 *$ \\
sport_belief_effort & 4.37 & 4.14 & 3.6 & .06 \\
sport_belief_deception & 2.42 & 2.36 & .13 & .72 \\
sport_belief_ability & 3.81 & 3.82 & .01 & .94 \\
sport_belief_external & 2.79 & 2.77 & .01 & .94 \\
\hline
\end{tabular}

Note: master_approach, master_avoid, perform_approach, perform_avoid - mean results in Achievement Goals Questionnaire for the respective factors, comp_sport - overall mean result in Perceived Sport Competence, sport_belief_effort, sport_belief_deception, sport_belief_ability, sport_belief_external - mean results in Sport Belief Questionnaire for the respective factors, $*=p<.05$.

Source: own study.

Table 2 presents the results of the series of multiple linear regression analyses that were conducted to test if perceived competence and beliefs about the causes of success (Effort, Ability, External Factors, Deception) predict athletes' results in the four achievement goals. The Enter method shows several significant predictors in the case of the mastery-approach goal: Effort $[\beta=.35, \mathrm{P}<.05]$, Deception $[\beta=-.25, \mathrm{P}<.05]$ and External Causes $[\beta=-.17, \mathrm{P}<.05]$, and one significant predictor in the case of both performance goals, Ability $[\beta=.23, \mathrm{P}<.05]$.

Table 2. Multiple regression analyses of links between motivational dispositions

\begin{tabular}{|c|c|c|c|c|c|c|c|c|}
\hline \multirow[t]{2}{*}{ Dispositions } & \multicolumn{2}{|c|}{$\begin{array}{l}\text { mastery- } \\
\text { approach }\end{array}$} & \multicolumn{2}{|c|}{$\begin{array}{l}\text { mastery- } \\
\text { avoid }\end{array}$} & \multicolumn{2}{|c|}{$\begin{array}{c}\text { performance- } \\
\text { approach }\end{array}$} & \multicolumn{2}{|c|}{$\begin{array}{c}\text { performance- } \\
\text { avoid }\end{array}$} \\
\hline & $\beta$ & $\mathbf{p}$ & $\boldsymbol{\beta}$ & $\mathbf{P}$ & $\beta$ & $\mathbf{p}$ & $\boldsymbol{\beta}$ & $\mathbf{P}$ \\
\hline sport_belief_effort & .35 & $.00 *$ & -.03 & .36 & .02 & .41 & .02 & .41 \\
\hline sport_belief_deception & -.25 & $.005 *$ & .006 & .48 & -.05 & .32 & -.05 & .32 \\
\hline sport_belief_ability & .14 & .07 & .06 & .28 & .23 & $.01 *$ & .23 & $.01 *$ \\
\hline sport_belief_external & -.17 & $.04 *$ & .02 & .41 & .01 & .47 & .01 & .47 \\
\hline comp_sport & -.003 & .49 & -.06 & .26 & -.08 & .21 & -.08 & .21 \\
\hline
\end{tabular}

Note: compare Note under Table 1.

Source: own study.

Figure 1 shows 3 profiles with intraindividual levels of motivation dispositions: achievement goals (masteryapproach, mastery-avoid, performance-approach, performance-avoid), perceived competence and beliefs about the causes of success (Effort, Ability, Deception, External Factors). The profiles were determined in nonhierarchical clustering with the k-means algorithm. This type of clustering, as was comprehensibly described by Wang and Biddle (2001), minimizes within-group variability and maximizes intergroup variability. Athletes' mean results in all motivation disposition variables were standardized to the $\mathrm{z}$ scale, where mean equals zero and standard deviation equals 1 . The analysis was conducted for 112 observations. Two outlying observations (results in Effort subscale below -3 in z scale) were excluded (compare: Wang \& Biddle, 2001). The three clusters solution was chosen as it allowed proportionate distributions of observations between the clusters.

The first cluster groups the 45 athletes who had high scores in all achievement goals (>.5z except for the mastery-avoid goal), average mean results $(<.5 \mathrm{z}$ and $>-.5 \mathrm{z})$ in perceived present competence and beliefs 
about all causes of success (Effort, Ability, Deception, External Factors). This cluster is labelled High Ambivalent Motivation.

The second cluster is composed of 32 athletes with high results in perceived present competence and belief that effort is the cause of success, average results in both mastery goals, average score in the belief that deception is the cause of success, low results $[<(-.5) z]$ in both performance goals and beliefs that ability and external factors are the causes of success. In view of the group's perception of their high competence and strong belief that effort is the cause of success, these athletes were referred to as Competence-Effort Oriented.

The third cluster comprises 32 athletes with high results in beliefs that ability and external factors are causes of success, average results in both performance goals, the mastery-avoid goal, perceived present competence, belief that effort and deception is the cause of success and low scores in the mastery-approach goal. This cluster was labelled Externally Oriented.

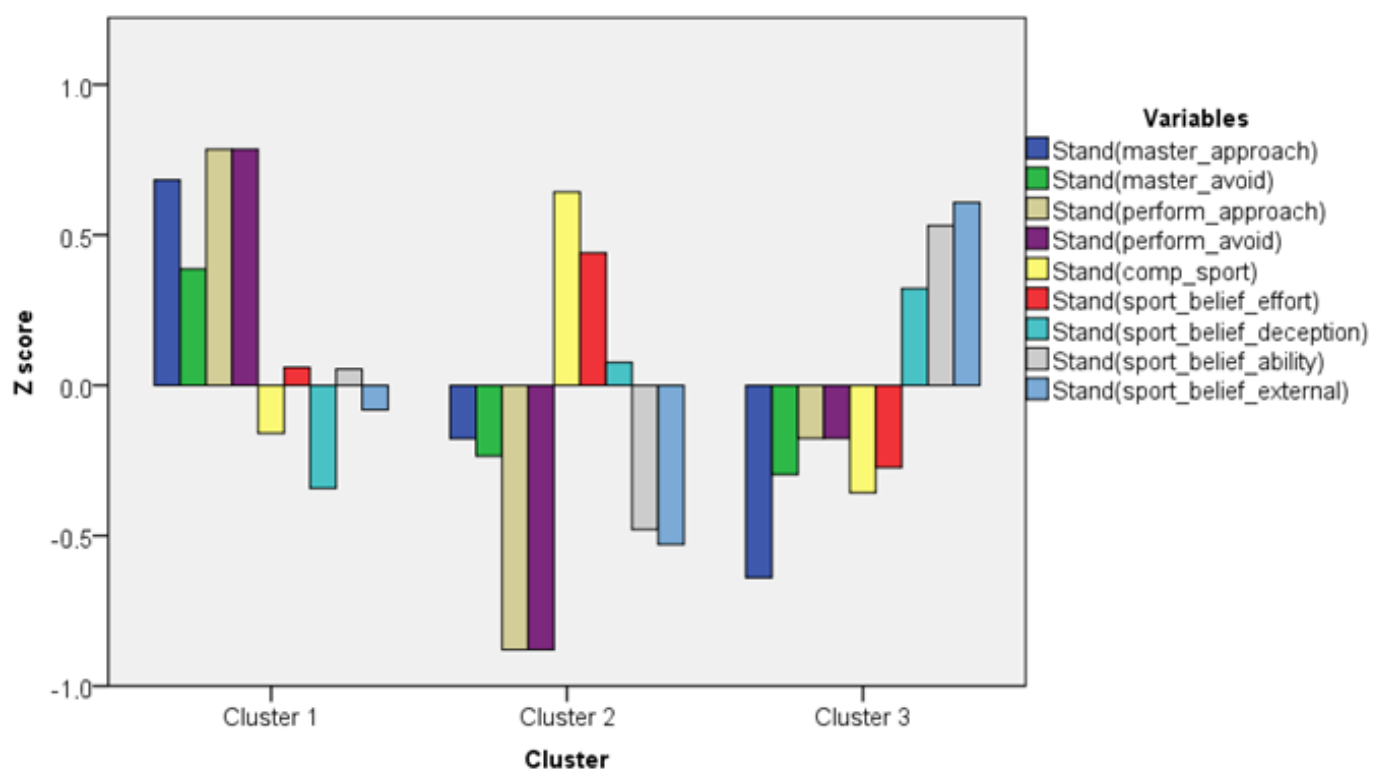

Figure 1. Intraindividual profiles of achievement motivation dispositions.

Note: Cluster 1 - High Ambivalent Motivation, Cluster 2 - Competence-Effort Oriented, Cluster 3 - Externally Oriented, variables - see Note under Table 1.

Source: own study.

In the next step, the chi square test of independence was calculated to check whether athletes in the three clusters differ regarding sporting level. Table 3 shows the number of elite and non-elite athletes in each cluster. A nonsignificant tendency was found $\chi^{2}(2)=5.14, \mathrm{P}=0,077$. There was similar number of elite and non-elite athletes in the first cluster, whereas clusters 2 and 3 differed in that there were more elite athletes in the second cluster and more non-elite athletes in the third cluster. There was no difference between clusters in the number of male and female athletes $\chi^{2}(2)=1.4, \mathrm{P}<0.05$. 
Table 3. Number of elite and non-elite athletes in each cluster

\begin{tabular}{llllll}
\hline & & \multicolumn{3}{c}{ Clusters } & \\
\cline { 3 - 5 } & & $\begin{array}{l}\text { High } \\
\text { Ambivalent } \\
\text { Motivation }\end{array}$ & $\begin{array}{l}\text { Competence- } \\
\text { Effort } \\
\text { Oriented }\end{array}$ & $\begin{array}{l}\text { Total } \\
\text { Oriented }\end{array}$ & \\
\hline Sporting level & Elite & 23.0 & 20.0 & 11.0 & 54.0 \\
& Expected & 22.3 & 15.9 & 15.9 & 54.0 \\
& Non-elite & 22.0 & 12.0 & 21.0 & 55.0 \\
& Expected & 22.7 & 16.1 & 16.1 & 55.0 \\
\hline
\end{tabular}

Note: see Notes under Table 1 and Figure 1.

Source: own study.

The last step was to examine the links between sporting level and motivational dispositions in each cluster separately. A MANOVA test with sporting level as an independent variable and beliefs about causes of success, perceived competence and four achievement goals as dependent variables showed no statistically significant main effect in any of the clusters. However, a follow up ANOVA showed a close to significant effect of sporting level on Effort in the first cluster $\mathrm{F}(1,45)=3.99, \mathrm{P}=.052$, which suggests a tendency for elite athletes to score higher in the Effort scale $(x=4.45, \mathrm{sd}=.47)$ than non-elite athletes $(\mathrm{x}=4.12, \mathrm{sd}=.64)$. Similarly, in the second cluster the sporting level was significantly related to both performance achievement goals $F(1,32)=7.55$ (for both goals $), \mathrm{P}=.01$. Elite athletes tended to score higher $(\mathrm{x}=4.11, \mathrm{sd}=7.55)$ than non-elite athletes $(\mathrm{x}=3.16, \mathrm{sd}=$ 1.21 ) in performance goals. In the third cluster, the sporting level had a significant effect on perceived competence $\mathrm{F}(1,32)=10.41, \mathrm{P}<.05$, and on the mastery-avoid achievement goal $\mathrm{F}(1,32)=6.86, \mathrm{P}<.05$. Among the athletes in this cluster, elite athletes perceived their competence as higher $(\mathrm{x}=3.51, \mathrm{sd}=.67)$ than non-elite athletes $(x=2.67, s d=.72)$. Also, non-elite athletes scored higher in the mastery-avoid achievement goal $(x=4.33, \mathrm{sd}=.79)$ than elite athletes $(x=3.58, \mathrm{sd}=.72)$.

\section{Discussion}

The aim of this study was to explore the links between sporting level and achievement motivation dispositions. The dispositions in this study comprised of achievement motivation goals, perceived competence, and implicit theories about the causes of success in sport. The results show that the athletes in the study appraised their competence according to their performance - elite sportspeople evaluated their competence higher than nonelite athletes. This effect is an outstanding difference between the two groups participating in the study and might indicate an adequate perception of competence in participants. Another possible explanation of the effect is that perception of competence influences performance. In this interpretation perception of high competence in elite-athletes would lead them to better sport performance and low evaluation of competence by non-elite athletes would hinder their achievement. A partial support for this proposition is that participants' sporting level, was determined by reference to standardised scale (compare: Gierczuk et al., 2012) and not solely by their current performance.

The analysis of the links between the dispositions in the general sample shows that the belief that effort is a cause of success is positively related to the mastery-approach goal, whereas beliefs that deception and external factors are causes of success are negatively related to this goal. These findings are in line with the most classic frameworks on achievement motivation goals (Dweck \& Leggett, 1988; Elliot \& Dweck, 1988). Significant links between the belief that ability is the cause of success in sport and both performance goals obtained in the study sample satisfy the theoretical hypothesis. On the other hand, the results of the study do not confirm the link between the belief that effort is the cause of success and the mastery-avoid goal. On the basis of assumptions made in the classic frameworks of the four achievement goals (Elliot \& McGregor, 2001), this outcome could be expected. However, a more recent meta-analysis of master-avoid goal correlates (Baranik et 
al., 2010) gives evidence for the empirical and conceptual distinctiveness of the goal. Our results may be interpreted as supporting the independence of the mastery-avoid goal in terms of its antecedents.

Wang and Biddle (2001) conducted cluster analysis of achievement motivation dispositions in the context of physical activity. Their findings show that the combination of multiple goals is related to a predisposition for engagement in competitive sport. Our study addresses achievement motivation characteristics among sportspeople. Cluster analysis determined three groups of athletes with specific motivation disposition profiles. The first group, referred to as The High Ambivalent Motivation, consists of a proportional number of elite and non-elite athletes. In comparison to athletes in other clusters, they scored high in the mastery-approach, performance-approach and performance-avoid goals, and average in perceived competence and different beliefs about the causes of success in sport. The within-cluster analysis of motivation disposition showed that elite athletes tend to score higher in the belief that effort is the cause of success in sport, as compared to the group of non-elite athletes. This finding is in line with hypothetical links between implicit theories and performance (Dweck, 1986); namely, athletes who believe that effort is the cause of success in sport put more effort into training and competition and perform better than other sportspeople.

A non-significant tendency is displayed by more elite than non-elite athletes in the second Competence-Effort Oriented cluster. Generally, sportspeople in this group perceive their competence as high, score low in both mastery and performance goals, and believe that effort, but not external causes or inborn talent, are causes of success. Closer examination of the interaction between the sporting level and the achievement dispositions in the cluster shows that elite athletes scored higher in performance goals than non-elite athletes. These findings give limited support to the assumptions of Sarrazin et al (Sarrazin et al., 1996; in: et al., 2003) that successful sportspeople adapt both incremental and entity theories about their athletic skills (Dweck \& Leggett, 1988).

The Externally Oriented cluster consists of athletes who scored high in the belief that inborn talent is the cause of success in sport and scored medium in perceived competence. Together with low results in the masteryapproach goal, this set of dispositions constitutes the least adaptive achievement motivation profile (Wang \& Biddle, 2001). The significant dominance of non-elite athletes in the cluster provides further confirmation of this. Moreover, the within-cluster analysis indicates that non-elite athletes in the cluster scored lower in perceived competence and higher in the mastery-avoid goal than elite athletes, as was expected (Duda \& Nicholls, 1992; White \& Duda, 1993).

Several limitations of the research need to be addressed. First, the study sample had to include a similar number of elite and non-elite athletes. This limited number of participants could have weakened the results obtained in the study. We observed a tendency for there to be more elite athletes in the second cluster and more non-elite athletes in the third; this could have been significant if a larger sample had been provided. Second, only track and field athletes participated. Lastly, the study focused on achievement motivation goals and their antecedents: implicit theories and perceived competence goals (Elliot \& Church, 1997). Other important lines of study in the context of achievement motivation include enjoyment of engagement in sport, amotivation, and the level of autonomy in sport (Wang \& Biddle, 2001; Wang, Biddle \& Elliot, 2007). These dispositions should be included in further studies with the participation of elite sportspeople.

\section{Practical implications}

More emphasis should be put on forming healthy concepts of competence and causes of success. Interpersonal comparisons of an athlete's performance and external explanations for it should be avoided by coaches and other sports professionals. 


\section{Conclusion}

The study aim was to explore achievement motivation dispositions in elite and non-elite track and field athletes. Disciplines which require years of training and preparation facilitate the development of achievement motivation. Some of the research findings are noteworthy. First of all, athletes seem to perceive their competence adequately: elite sportspeople scored higher in Perceived Sport Competence than non-elite athletes. Second, the results support not only the classic assumptions (Dweck \& Leggett, 1988) about the links between implicit theories and the mastery-approach goal, but also more current findings (Baranik et al., 2010) relating to the mastery-avoid goal. Finally, the study reveals three distinct achievement motivation profiles which partially coincide with the patterns of achievement dispositions obtained in the context of physical activity.

\section{Acknowledgements}

We would like to thank all the track and field athletes who participated in the study. We also thank professor Czesław Noworol for invaluable comments regarding statistical analysis, professor Kamila Wojdyłło for sharing tools essential for the study, dr Grzegorz Głąb, track and field coaches, who helped in data gathering and Jagiellonian University.

\section{Ethics approval and informed consent}

Ethics approval for the study was granted by The Institutional Research Ethics Board residing in Institute of Psychology at Jagiellonian University.

\section{Competing interests}

No potential conflict of interest was reported by the authors.

\section{Funding}

This research received no specific funds from any public or private funding agencies.

\section{REFERENCES}

Baranik, L.E., Bynum, B.H., Stanley, L.J. \& Lance, C.E. (2010). Examining the Construct Validity of Mastery - Avoidance Achievement Goals: A Meta - Analysis. Human Performance, 23, 265-282. DOI: 10.1080/08959285.2010.488463.

Bedyńska, S. \& Cypryańska, M. (Ed.) (2013). Zaawansowane metody tworzenia wskaźników- eksploracyjna analiza czynnikowa i testowanie rzetelności skali /Advanced methods of indicators creation - explanatory factor analysis and scale reliability testing/. In S. Bedyńska \& M. Cypryańska (Eds.), Statystyczny drogowskaz 1. Praktyczne wprowadzenie do wnioskowania statystycznego /Statistical signpoint 1. Practical Introduction to statistical inference/ (pp. 245-283). Warszawa: Wydawnictwo Akademickie Sedno.

Biddle, S.J.H., Wang, C.K.J., Chatzisarantis, N.L.D. \& Spray, C.M. (2003). Motivation for physical activity in young people: entity and incremental beliefs about athletic ability. Journal of Sport Sciences, 21, 973-989. DOI: $10.1080 / 02640410310001641377$.

Dąbrowska, H. (1991). Motywacja osiągnięć w sporcie [Achievement amotivation in sport]. In T. Tyszka (Ed.), Psychologia i sport /Sport and Psychology/ (pp. 28-54). Warszawa: Wydawnictwo AWF.

Duda, J.L. \& Nicholls, J.G. (1992). Dimensions of achievement motivation in schoolwork and sport. Journal of Educational Psychology, 84, 290-299.

Dweck, C.S. \& Leggett, E.L. (1988). A social- cognitive approach to motivation and personality. Psychological Review, 95, 256-273. 
Dweck, C.S. (1986). Motivational processes affecting learning. American Psychologist, 41, 1040-1048.

Elliot, E.S. \& Dweck, C.S. (1988). Goals: and approach to motivation and achievement. Journal of Personality and Social Psychology, 54, 5-12. DOI:10.1037/0022-3514.54.1.5.

Elliot, A.J. \& McGregor, H. A. (2001). A 2x2 achievement goal framework. Journal of Personality and Social Psychology, 80, 501-519. DOI: 10.1O37//OO22-3514.80.3.501.

Gierczuk, D., Bujak, Z., Rowiński, J. \& Dmitriyew, A. (2012). Selected coordination motor abilities in elite wrestlers and taekwon-do competitors. Polish Journal of Sport and Tourism, 19, 230-234. DOI: https://doi.org/10.2478/v10197-0120022-1.

Jagacinski, C.M. \& Strickland, O.J. (2000). Task and ego orientation. The role of goal orientations in anticipated affective reactions to achievement outcomes. Learning and Individual Differences, 12, 189-208.

Jang, L.Y. \& Liu, W.C. (2012). 2x2 achievement goals and achievement emotions: a cluster analysis of students' motivation, European Journal of Psychology of Education, 27, 59-76. DOI: 10.1007/s10212-011-0066-5.

Juczyński, Z. (2000). Poczucie własnej skuteczności - Teoria i Pomiar /Self-efficacy - Theory and Measurement/. Folia Psychologica, 4, 11-24.

McClelland, D.C. (1955). Some social consequences of achievement motivation. Nebraska symposium on motivation, Lincoln: University of Nebraska Press.

McClelland, D.C. (1986). Human Motivation. Glenview: Scott, Foresman and Co.

Midgley, C. \& Urdan, T. (2001). Academic self-handicapping and achievement goals: a further examination. Contemporary Educational Psychology, 26, 61-75. DOI:10.1006/ceps.2000.1041

Moller, A.C. \& Elliot, A.J. (2006). The 2x2 achievement goal framework: an overview of empirical research, In A.V. Mitel (Ed.), Focus on educational psychology (pp. 307-326). Nova Science Publishers. DOI: 10.1080/00461520.2011.538646.

Negru, O. (2009). Achievement goals: Defining competence and understanding performance. Economy Transdisciplinary Cognition, 2, 71-79. Retrieved from https://search.proquest.com/docview/757936184?accountid=11664.

Nicholls, J.G. (1984). Achievement motivation: conceptions of ability, subjective experience, task choice, and performance. Psychological Review, 91, 328-346.

Nien, C.L. \& Duda, J.L. (2008). Antecedents and consequences of approach and avoidance achievement goals: A test of gender invariance. Psychology of Sport and Exercise, 9, 352-372. DOI: 10.1016/j.psychsport.2007.05.002.

Spray, C.M., Wang, C.K.J., Biddle, S.J.H., Chatzsisarantis, N.L.D. \& Warburton, V.E. (2006). An experimental test of self- theories of ability in youth sport. Psychology of Sport and Exercise, 7, 255-267. DOI: $10.1016 /$ j.psychsport.2005.05.001.

Swann, C.F., Moran, A. \& Piggott, D. (2015). Defining elite athletes: issues in the study of expert performance in sport psychology. Psychology of Sport and Exercise, 16, 3-14. DOI: http://dx.doi.org/10.1016/j.psychsport.2014.07.004.

Tokarz, A. \& Kaleńska-Rodzaj, J. (2011). Orientacje motywacyjne jako wyjaśnienie specyfiki motywu /Ego-task orientation as a tool of motive explanation/. In A. Tokarz (Ed.) Pamięć. Osobowość. Osoba. Księga Dedykowana prof. Annie Gałdowej /Memory. Personality. Person. The Book Dedicated to prof. Anna Galdowa/ (pp. 281-295). Kraków: WUJ.

Wang, C.K. J. \& Biddle, S.J.H. (2003). Intrinsic motivation toward sports in Singaporean students: the role of sport ability beliefs, Journal of Health Psychology, 8, 515-523. DOI: 10.1177/13591053030085004.

Wang, C.K.J., Biddle, S.J.H. \& Elliot, A.J. (2007). The 2x2 achievement goal framework in a physical education context. Psychology of Sport and Exercise, 8, 147-168. DOI: http://dx.doi.org/10.1016/j.psychsport.2005.08.012.

White, S.A. \& Duda, J.L. (1993). Dimensions of goals and beliefs among adolescent athletes with physical disabilities. Adapted Physical Activity Quarterly, 10, 125-136.

Wojdyło, K. \& Retowski, S. (2012). Kwestionariusz Celów Związanych z Osiągnięciami (KCO) - konstrukcja i charakterystyka psychometryczna /Achievement Goals Questionnaire (KCO) - tool construction and psychometric analysis/. Przegląd Psychologiczny, 55, 9-28. 
Van- Yperen, N.W. \& Duda, J.L. (1999). Goals orientations, beliefs about success, and performance improvement among young elite Dutch soccer players. Scandinavian Journal of Medicine and Science in Sports, 9, 358-364. DOI: $10.1177 / 0146167206292093$.

\section{AUTHOR'S ADDRESS:}

Anna Pietrzak

Instytut Psychologii

Uniwersytet Jagielloński

ul. Ingardena 6, Kraków

annam.pietrzak@doctoral.uj.edu.pl

Aleksandra Tokarz

Instytut Psychologii

Uniwersytet Jagielloński

ul. Ingardena 6, Kraków

aleksandra.tokarz@uj.edu.pl

Received: 5 November; Accepted: 2 July 2019 